\title{
The IMIA Yearbook of Medical Informatics - Objectives, Contents, Formats -
}

Since its inception in 1992 the IMIA Yearbook of Medical Informatics has been one of the most visible and valuable "products" that the International Medical Informatics Association (IMIA) provides - not only to its members but to the health and biomedical informatics community at large.

\section{Objectives and Target Audience of the IMIA Yearbook of Medical Informatics}

\section{Objectives:}

- To present an overview of the most original, excellent state-of-the-art research in the area of health and biomedical informatics of the past year.

- To provide surveys about the recent developments, and comprehensive reviews on relevant topics in this field.

- To provide information about IMIA.
Target audience:

- Health and biomedical informatics scientists in research, education, and practice worldwide.

- Health care professionals interested in current health and biomedical informatics research results.

- Health and biomedical informatics students and postgraduates.

- Scientists and professionals with shared interests in biomedical informatics.

Due to changing demands by its readership and new technology and opportunities, from 2006 on the IMIA Yearbook of Medical Informatics has been modified in content as well as in its mode of publication. The objective is to position the IMIA Yearbook to meet the future needs of its readership and to substantially broaden its availability to virtually all members of the IMIA family. In particular, surveys, giving overviews of recent developments, and comprehensive introductory reviews on relevant topics in the different fields of health and biomedical informatics, have been added as original articles.

The IMIA Yearbook of Medical Informatics appears as a supplement of Methods of Information in Medicine, one of the official journals of IMIA. As a consequence, all original papers are peer reviewed, Medline indexed, and impact factor listed. The Yearbook remains a non-profit publication of IMIA, jointly published with Schattauer Verlag.

\section{Contents of the IMIA Yearbook of Medical Informatics}

- Foreword from the IMIA President, editorial

- Keynote paper on the Yearbook's annual special topic

- Surveys of recent developments, corresponding to the fields of the Yearbook sections ${ }^{1}$

- Traditional best paper selection with short synopses as introductions

- Comprehensive reviews on relevant topics from health and biomedical informatics.

- Articles on research and educational programs

- History of medical informatics section with original papers on the history of medical informatics and reprints of 'classic' articles

- Information on IMIA and on IMIA Regional Groups

\footnotetext{
'health and clinical management", 'human factors', "health information systems', 'sensor, signal and imaging informatics', 'decision support, knowledge representation and management', 'education and consumer informatics', 'bioinformatics" and the special topic section (section names as in the Yearbook 2008, topics are regularly updated)
} 
The IMIA Yearbook of Medical Informatics is published in three formats:

- The Full Electronic Version contains full length original articles and content summaries of the selected best papers. In addition, those selected best papers are republished, where permission has been given by the respective copyright holders. Schattauer Verlag provides online hosting of the Yearbook's Full Electronic Version. The Full Electronic Version of the new IMIA Yearbook of Medical Informatics can be accessed by all members of IMIA's National Societies, provided that the respective National Society has subscribed the Full Electronic Version. Faculty and students of IMIA's Institutional Academic Members also can have access to the Full Electronic Version as well as IMIA Institutional Corporate Members and subscribers of the journal Methods of Information in Medicine.

- The Paper Version also contains the full length original articles as well as the content summaries of the selected best papers. It appears as a supplement of the journal Methods of Information in Medicine with a size of approximately 250 pages. The Paper Version includes online access to the complete Full Electronic Version. The Paper Version is made available to those major medical informatics conferences, which wish to tie-in with the IMIA Yearbook such as MIE or Medinfo. Single copies can be ordered from Schattauer Verlag ${ }^{1}$. They are available at a reduced rate for members of IMIA's National Societies ${ }^{2}$, and to subscribers of Methods of Information in Medicine ${ }^{3}$.

- The Standard Electronic Version contains abstracts of the original articles, the foreword from the IMIA President, the editorial, and information on IMIA. Schattauer Verlag provides online hosting of the Yearbook's Standard Electronic Version. The Standard Electronic Version of the New IMIA Yearbook of Medical Informatics can be accessed by all members of IMIA's National Societies.

For further information please contact:

IMIA Yearbook Editorial Office Martina Hutter

University Hospitals Heidelberg ZIM

Tiergartenstr. 15

D-69121 Heidelberg, Germany

Phone: +49 6221 56-2002

Fax +49 6221 56-2004

e-mail: yearbook@imiapubs.org
IMIA Executive Director Steven Huesing 5782 - 172 Street Edmonton, Alberta Canada T6M 1B4 Phone: +1-780-489-4531

Fax: +1-780-489-3290

e-mail: imia@shaw.ca
IMIA on WWW:

http://www.imia.org

\footnotetext{
95.00 - for single orders (incl. surface shipping, plus VAT, if tax regulations are requiring it)

47.50• for single orders (incl. surface shipping, plus VAT, if tax regulations are requiring it) and $35.00 \bullet$ for bulk orders ( 20 or up, incl. surface shipping, plus VAT, if tax regulations are requiring it)

24.75 (incl. surface shipping, plus VAT, if tax regulations are requiring it)
} 